\title{
Guerreiras Donzelas: uma experiência de teatro feminista para crianças
} Warrior Maidens: an experience on feminist theatre for children

Jussyanne Rodrigues Emidio ${ }^{1}$

Luane Pedroso ${ }^{2}$ 


\section{Resumo}

Este trabalho, escrito por duas autoras, pretende ser um breve relato sobre a elaboração do espetáculo infanto-juvenil Guerreiras Donzelas (2017). A peça apresenta as trajetórias de duas guerreiras, a francesa Joana d'Arc e a lenda chinesa de Hua Mulan. Produzido a partir de uma disciplina da pós-graduação, o trabalho reflete sobre a figura arquetípica da Donzela Guerreira e a sua materialização em mulheres reais ao longo dos tempos. Dessa maneira, aliado às práticas teatrais feministas, a peça traz alguns aspectos dos feminismos e das suas pautas de maneira lúdica para crianças, adultas e adultos.

Palavras-chave: Guerreiras Donzelas; dramaturgia feminista; teatros feministas

\section{Abstract}

This work intends to make a brief report about the elaboration of the children and youth spectacle Warrior Maidens (2017) and it is written by two authors. The play features the trajectories of two warriors, the French Joan of Arc and the Chinese legend of Hua Mulan. The play reflects about the archetypal figure of the Warrior Maiden and its materialization in real women throughout the ages and was produced from a postgraduate discipline. In this way, together with feminist theatrical practices, the play brings some aspects of feminism and its guidelines in a playful way for children, adults and adults.

Keywords: Warrior Maidens; feminist dramaturgy; feminist theatres
ISSN: 1414.5731

E-ISSN: 2358.6958

${ }^{1}$ Doutoranda do Programa de Pós-graduação em Teatro - PPGT/UDESC. Atriz, bailarina, diretora. jussyemidio@gmail.com 


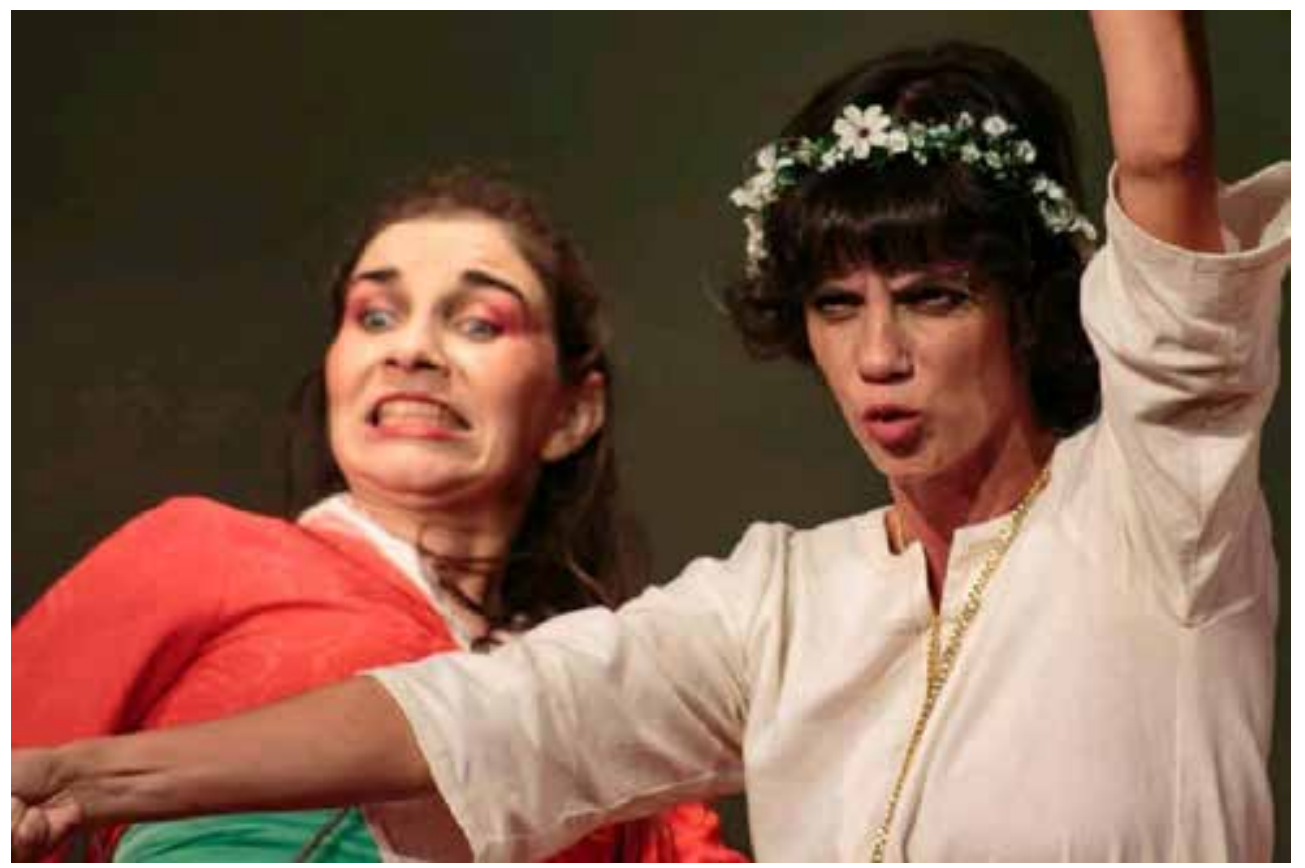

Jussyanne Emidio e Luane Pedroso. Teatro da UFSC. Florianópolis. 20 maio 2018. Foto: Mhirley Lopes. Acervo pessoal das autoras.

O projeto Guerreiras Donzelas surgiu do desejo de tratar temáticas feministas e de direitos das mulheres de maneira lúdica voltada ao público infanto-juvenil ancorando-se na perspectiva histórico-lendária de duas personagens, a francesa Joana d'Arc e a chinesa Hua Mulan. Surgido no meio universitário, o trabalho teve seu início vinculado à disciplina: Seminário Temático I - Introdução ao Teatro Feminista, ministrada pela professora Doutora Maria Brígida de Miranda no primeiro semestre de 2017, disciplina integrante do Programa de Pós-graduação em Teatro (PPGT/UDESC), e cursada por nós, Jussyanne Emidio e Luane Pedroso. Na ementa, Miranda aponta a proposta delineada para o curso:

\footnotetext{
"O que é Teatro Feminista?"

é a questão guia deste curso. Enquanto campo de estudos o "Teatro Feminista" conjuga práticas teatrais, movimentos feministas, teoria crítica feminista, filosofia, historiografia, ativismo político e uma pletora de movimentos sociais. Além deste aspecto rizomático o Teatro Feminista como prática e construção epistemológica floresce em diversos contextos geo-político-culturais, o que lhe confere uma pluralidade de histórias, teorias, políticas, ativismos e práticas teatrais. Este curso pretende pontuar algumas das origens e manifestações de teatros feministas e propõe estudos de caso para refletir sobre as tensões entre teoria, estética e ativismo. (Miranda, 2017, p. 2)
}

Quando começamos a trabalhar nos projetos de ambas em conjunto, a peça foi ganhando os contornos de contação de histórias infanto-juvenil. Embora no início do processo a ideia inicial fosse a de uma peça destinada ao público adulto, optamos por destiná-lo ao público infanto-juvenil e, com isso, as modificações no enredo e estética trouxeram uma linguagem mais lúdica e acessível a essa faixa etária com a qual estávamos dispostas a dialogar. A mudança do público-alvo se deu por entendermos a necessidade de trazer temáticas que abordassem aspectos do feminismo também para crianças, além do desejo de narrar, por meio da arte, as consequências que pensamentos radicais e intolerantes podem acarretar, como podemos transformá-los 
e ainda como o teatro pode trazer elementos de pautas feministas de forma poética que dialoguem com o público infanto-juvenil.

A seguir, detalharemos alguns dos aspectos mais relevantes na elaboração do espetáculo: os estudos sobre a Donzela Guerreira, a construção dramatúrgica, colaborações que tivemos e a direção de Brígida Miranda que, após a primeira apresentação, em agosto de 2017, se interessou em dirigir o trabalho, ocasionando uma reestreia em novo formato.

\section{A figura arquetípica da Donzela Guerreira}

A Donzela Guerreira, figura arquetípica que necessita se disfarçar de homem para guerrear e que habita o inconsciente coletivo ${ }^{3}$, ressurge em diversas épocas da história da humanidade e foi mote para diversas criações ao longo da história, tais como a personagem Diadorin, do livro Grande Sertão: Veredas (do escritor brasileiro Guimarães Rosa), a cantiga popular de origem ibérica A Donzela que foi à Guerra, a lenda chinesa de Hua Mulan, além de histórias de mulheres reais como as de Maria Bonita, Anita Garibaldi e Joana d'Arc.

Um dos principais estudos no Brasil sobre a figura da Donzela Guerreira, no qual Jussyanne Emidio se baseou desde a proposta inicial do solo, é o livro da autora Walnice Galvão, A donzela-guerreira: um estudo de gênero (Galvão, 1998), que delineia e estabelece comparações entre a figura arquetípica da donzela guerreira e outras personagens mitológicas (como Palas Atena, deusa grega) e históricas (a exemplo de Joana d'Arc). Galvão inicia a delinear a figura arquetípica da seguinte forma:

Essa personagem frequenta a literatura, as civilizações, as culturas, a história, a mitologia. Filha de pai sem concurso de mãe, seu destino é assexuado, não pode ter amante nem filho. Interrompe a cadeia das gerações, como se fosse um desvio do tronco central e a natureza a abandonasse por inviabilidade. Sua potência vital é voltada para trás, para o pai; enquanto ela for só do pai, não tomará outro homem. Mulher maior, de um lado, acima da determinação anatômica; menor, de outro, suspensa do acesso à maturidade, presa ao laço paterno, mutilada nos múltiplos papéis que natureza e sociedade lhe oferecem. (Galvão, 1998, p. 11-12)

Walnice Galvão traz, nesse parágrafo, importantes questões para a discussão. Ao prever que a Donzela Guerreira possui destino assexuado, vimos que muitas heroínas não se enquadram nesse quesito: algumas, como Anita Garibaldi e Maria Bonita, acabam por possuir companheiro, filho (ou ambos). Assim como Galvão também enuncia, há diferenças entre o arquétipo da Donzela Guerreira e outros arquétipos evocados em personagens que escapam a esse padrão, como Joana d'Arc e Hua Mulan. Além disso, optamos por demonstrar, na peça, a perspectiva de uma mulher cisgênera que se disfarça de homem cisgênero por questões de aceitação social em espaços masculinos, mas mantém sob o disfarce as suas características da cisgeneridade feminina.

\footnotetext{
${ }^{3}$ Como figura arquetípica, a Donzela Guerreira pode ser encarada como o que o psicanalista suíço Carl Gustav Jung [1875-1961] denominou arquétipos. Para Jung (2011), os arquétipos são imagens que funcionam como modelos comportamentais e que são o material constitutivo do inconsciente coletivo, que seria uma parcela do inconsciente repassada por herança entre as gerações. Diferentemente do inconsciente pessoal, cujos conteúdos já estiveram conscientes e foram forjados nas experiências pessoais, os conteúdos do inconsciente coletivo não são constituídos de forma individual, e sim transmitidos hereditariamente (Jung, 2011).
} 
Como mulher cindida entre os papéis que lhes são oferecidos, a Donzela Guerreira é uma figura possível em decorrência da definição rígida de papéis de gênero num dado contexto social, onde as fronteiras entre o masculino e feminino precisam estar identificadas até mesmo nas suas vestimentas, para que não reste a menor dúvida sobre qual papel sexual e de gênero cada pessoa deve desempenhar. Nesses contextos, não reconhecer que diversas características reconhecíveis como "masculinas" também fazem parte de mulheres (sendo a recíproca também verdadeira) é perpetuar os rígidos limites de gênero existentes entre corpos femininos e masculinos, bem como dos seus atributos, responsabilidades sociais e desejos.

Walnice Galvão segue delineando a figura arquetípica e seus traços comportamentais recorrentes nas narrativas:

\begin{abstract}
Os traços básicos da personagem mantêm sempre uma mesma configuração, privilegiadora de algumas áreas da personalidade. Sua posição é numinosa na série filial, como primogênita ou unigênita, às vezes a caçula; o pai não tem filhos homens adultos ou, o que é quase regra, não os tem de todo. Ela corta os cabelos, enverga trajes masculinos, abdica das fraquezas femininas - faceirice, esquivança, sustos - cinge os seios e as ancas, trata seus ferimentos em segredo, assim como se banha escondido. Costuma ser descoberta quando, ferida, o corpo é desvendado; e guerreia; e morre. (Galvão, 1998, p. 12)
\end{abstract}

A responsabilidade filial da donzela é um fator curioso que foi por nós contestada posteriormente na dramaturgia, a partir de uma observação que nos foi feita logo na primeira apresentação que fizemos, pela Doutora Barbara Biscaro ${ }^{4}$, o ato de responsabilizar-se e cuidar do pai, dos irmãos menores - ou seja, da família - é um fator que poderia reforçar certo estereótipo do gênero feminino do cuidado. Voltaremos a esse tópico quando tratarmos, adiante, da construção da dramaturgia. Baseadas nesses aspectos, Jussyanne Emidio e Luane Pedroso escolheram duas personagens para serem retratadas na peça.

\title{
A escolha de nossas Donzelas Guerreiras - Joana e Mulan
}

A partir do estudo de Galvão (1998), Joana foi escolhida por Luane pela sua popularidade como santa e por estar presente no imaginário ocidental, e Mulan foi escolhida por Jussyanne por ter possível aproximação com o imaginário infantil, já que foi tema de um filme de animação da Walt Disney Animation Studios ${ }^{5}$ há cerca de 20 anos.

Joana D'Arc circula entre livros didáticos de história, cinema, festas a fantasia, poemas e canções. Alguns filmes são: Jeanne D'Arc de 1899, com direção do Georges Méliès; A paixão de Joana de 1928, direção de Carl Theodor Dreyer; Joan of Arc de 1948, do diretor Vitor Fleming; e o Jeanne D'Arc de 1999, com direção de Luc Besson. Já na literatura, há um escrito do filósofo iluminista francês Voltaire (2018), intitulado La Pucelle de D' Orléans, que data de 1730, no qual ele descreve uma Joana não

\footnotetext{
${ }^{4}$ Barbara Biscaro é Doutora em Teatro (UDESC) e atua como professora colaboradora no Departamento de Artes Cênicas da UDESC.

${ }^{5}$ O filme de animação Mulan (1998), foi dirigido por Tony Bancroft e Barry Cook, produzido e distribuído pela empresa de entretenimento estadunidense Walt Disney Animation Studios.
} 
heroína, mas vítima do fanatismo religioso e corrupção da Idade Média. Ainda nesse poema, o filósofo satiriza a figura de Joana D'Arc. Vale ressaltar que Voltaire viveu na França permeada pelas primeiras ideias iluministas as quais rejeitavam muito o que a Idade Média, ou Idade das Trevas (para os iluministas) trazia.

Fazendo referência a Voltaire, Mayquel Ferreira Eleuthério (2012), em seu artigo O Filósofo e a Donzela: a corrosão do mito de Joana d'Arc por Voltaire em La Pucelle d'Orléans, aponta que:

Joana, vendida por Jean de Luxemburgo aos ingleses, e, após, com o esforço da Sorbonne, presa da Santa Inquisição, foi submetida a um injusto processo, que Voltaire relata sublinhando a corrupção da Igreja: 'E uma infeliz simplória, que tinha tido coragem o bastante para render enormes serviços ao rei e à pátria, foi condenada à fogueira por quarenta e quatro padres franceses que a imolaram à facção da Inglaterra'. Não há o herói na versão voltairiana da história de Joana, apenas a vítima (Ferreira Eleutherio, 2012, p. 141).

Nesse ponto, Luane entra em concordância com o pensamento de Voltaire. Os feitos heroicos de Joana não foram suficientes para livrá-la da fogueira: mesmo tendo ajudado a França, ela foi vendida e condenada. Em 1431, data de sua morte, Joana D'Arc era uma herege e não uma heroína.

De acordo com a historiadora Flávia Aparecida Amaral (2012), no início da Revolução Francesa (ocorrida em 1789), os revolucionários queriam romper com tudo aquilo que lembrava a Idade Média. Destruíram vários ícones, entre eles estátuas de Joana D'Arc que era vista como símbolo da monarquia francesa. Após a revolução em 1801, mesmo sendo de opinião controversa, Napoleão, então cônsul, permitiu a reconstrução de uma estátua de Joana D'Arc, fazendo referência à donzela como símbolo de luta do povo francês (Amaral, 2012). A ressignificação dos símbolos pelos revolucionários mais liberais reconstruiu e acoplou valores burgueses à Joana, fazendo dela um símbolo da nova fase francesa, de acordo com os novos ideais iluministas.

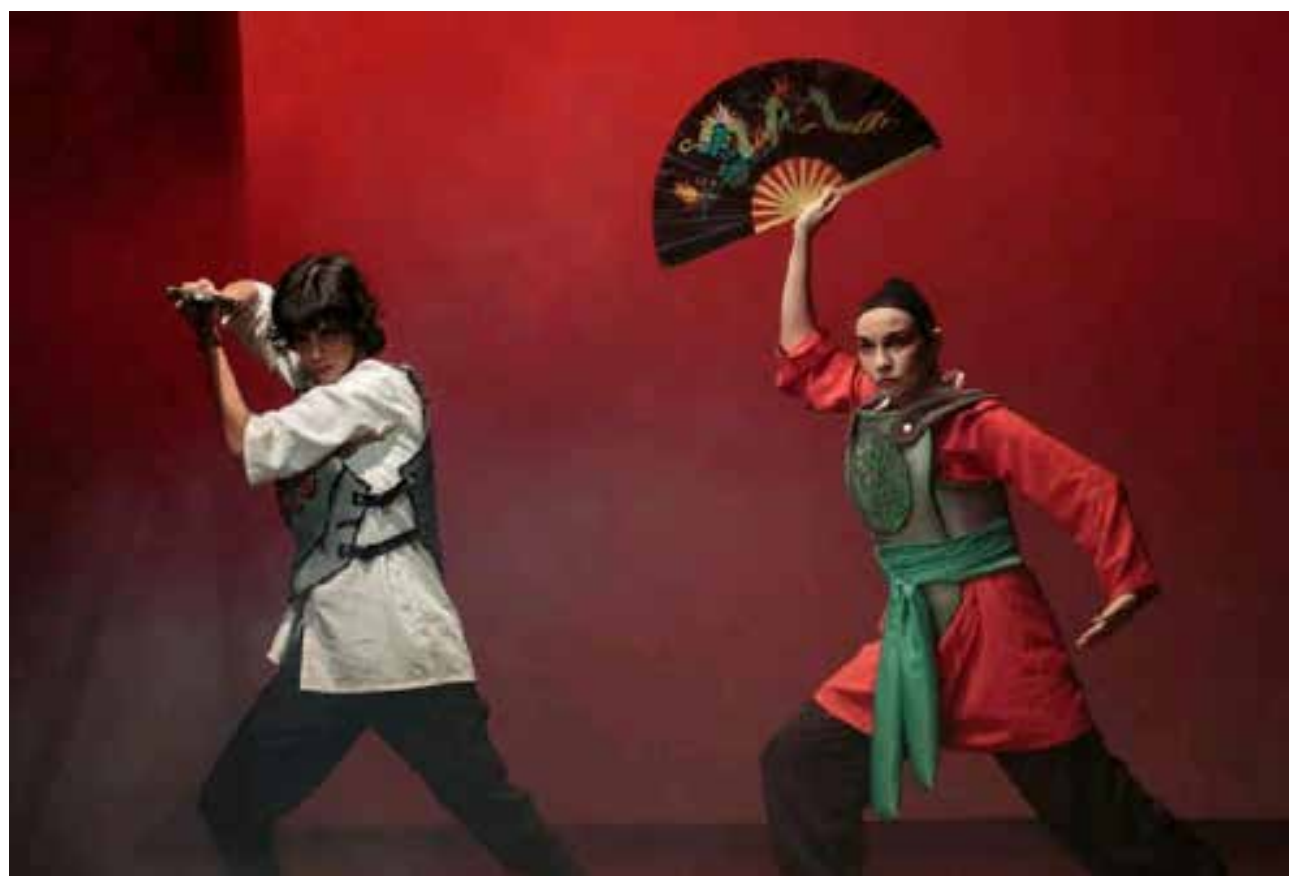

Luane Pedroso e Jussyanne Emidio. Teatro da UFSC. Florianópolis. 20 maio 2018. Foto: Mhirley Lopes. Acervo pessoal das autoras. 
Mulan, escolhida por Jussyanne, foi trazida à dramaturgia devido à possibilidade de aproximação ao imaginário das crianças. A personagem é conhecida entre o público infantil, principalmente por causa do longa-metragem de animação Mulan (1998) da Walt Disney Animation Studios, que foi um filme que também permeou a infância e adolescência de Jussyanne. Em uma época onde as principais personagens femininas das animações ainda possuíam fortemente a demarcação de "princesas", Mulan foi uma das primeiras personagens da cultura de massa da animação que mostrou a um público infanto-juvenil outra possibilidade para o gênero feminino, mesmo que ainda se encontrasse sob disfarce. Dessa maneira, a dramaturgia foi inicialmente desenvolvida para que apresentassem as duas personagens como narradoras, mas também representássemos a ambas, se tornando uma contação de estórias em que as personagens não estariam fixas, mas pudessem se transformar no decorrer do espetáculo.

\section{Contando histórias de mulheres - elaboração da dramaturgia}

Contar histórias de mulheres tem sido uma das estratégias do feminismo para diminuir o apagamento sistemático que diversas mulheres tiveram ao longo da história da humanidade, quando as narrativas históricas somente eram compostas por, para e sobre os homens. Sobre essa questão, a estudiosa Elaine Aston ${ }^{6}$, em seu livro An introduction to feminism and theatre (1995), aborda os estudos de teatros feministas e a mudança que tais estudos vêm propondo aos cânones teatrais, onde a presença feminina ainda é rara não somente na autoria dramatúrgica reverenciada, mas também em funções de liderança como direção:

Compreender as condições culturais e materiais do teatro no passado (e no presente) é central para um re-enquadramento feminista da história do teatro, que possui os seus próprios questionamentos a fazer sobre como e por que os trabalhos de mulheres foram "escondidos" ou marginalizados (Aston, 1995, p. 2, tradução livre de Jussyanne Emidio) ${ }^{7}$

A partir da proposta da disciplina Seminário Temático I - Introdução ao Teatro Feminista, mencionada anteriormente, além do foco em trabalhos feitos por mulheres, que obtiveram sucesso em seu tempo mas não foram inseridas na historiografia teatral (a exemplo da estadunidense Susan Glaspell [1876-1948] e da brasileira Josefina Álvares de Azevedo [1851-1913], ambas jornalistas e dramaturgas), observamos também as questões que envolvem a representação feminina nos textos dramatúrgicos considerados basilares. Tais textos foram escritos por homens, em sua maioria, com personagens femininas voltadas ao olhar do espectador masculino e segundo o imaginário masculino do que é ser, pensar e agir como mulher. Para Aston, nesse intento, os estudos da teoria crítica feminista no teatro buscaram estudos na literatura, cinema e outras mídias:

\footnotetext{
${ }^{6}$ Elaine Aston é professora na Lancaster University, voltada ao ensino de teatro britânico e práticas teatrais contemporâneas, e pesquisadora de teatro feminista no Reino Unido.

${ }^{7}$ Understanding the cultural and material conditions of theatre past (and present) is central to a feminist re-framing of theatre history, which has its own questions to ask about how and why women's work has been 'hidden' or marginalized
} 
Ao contrário de sua "irmã" literária, entretanto, o estudo feminista do teatro tinha não só que "resistir" ao texto escrito ou relê-lo, mas também necessitou encontrar maneiras de "leitura" sobre o contexto das performances. Os estudos do teatro olharam para os estudos fílmicos e midiáticos onde os conhecimentos feministas focaram na construção de "mulher" como um signo: uma abordagem na qual o feminismo, a psicanálise e Semiótica foram e estão sendo utilizadas para entender como as mulheres são representadas em textos cinematográficos e outros contextos culturais (Aston, 1995, p. 5. Tradução livre de Jussyanne Emidio) ${ }^{8}$

Como já exposto anteriormente, as referências para as personagens evocadas na dramaturgia de Guerreiras Donzelas emergem do nosso contexto cultural, sejam ícones historiográficos, lendários e presentes na cultura de entretenimento. Compreendemos que representações culturais constroem nossas percepções e recepções de mundo, e que o teatro feminista tem maneiras de construir outras possibilidades de representação para mulheres. Dessa forma, observando as representações de mulheres que traríamos à cena, e colocando duas mulheres narrando os feitos de outras duas mulheres, Joana d'Arc e Mulan, a dramaturgia foi composta por nós duas, Luane e Jussyanne, por meio de improvisos cênicos em texto, dança e animação de objetos.

Duas frases que nos guiaram na contação de histórias foram lemas tais como "Juntas somos mais fortes" e "Lute como uma garota", que enfatizam a força feminina, a empatia e a rede colaborativa entre mulheres - sororidade - ao invés da rivalidade. Dessa forma, as personagens que habitam lugares e épocas históricas diferentes encontram-se em cena a partir das contadoras, que revelam que essa pode ser a história de muitas outras mulheres.

Escolhidas as personagens, iniciamos a elaboração do texto base. Os ensaios ocorreram entre os meses de julho e agosto de 2017, nas salas do Departamento de Artes Cênicas (DAC/CEART/UDESC). Aos poucos, criando coreografias e pequenas cenas, fomos delineando algumas células que compuseram o formato final, bem como alguns elementos que seriam utilizados.

A história da chinesa Mulan estava mais desenhada, com uma canção e com linha dramática mais definida, pois Jussyanne já havia pesquisado sobre essa figura desde a época de sua graduação. Porém, o texto que contaria a história de Joana teria que ser construído. Começamos a composição dele conversando sobre o que sabíamos acerca deste outro mito em um diálogo entre Luane e Jussyanne mais ou menos assim:

Joana era camponesa, foi pra guerra e foi pega pelos inquisidores;

Joana se disfarçou, foi pra guerra e lá foi descoberta;

Joana era muito religiosa, foi pra guerra por causa de um chamado divino, quando descoberta foi pra fogueira;

Joana foi vista como bruxa, a fogueira era a pena que sofriam as pessoas que eram condenadas por bruxaria.

\footnotetext{
${ }^{8}$ Unlike its literary "sister", howewer, the feminist study of theatre had not only to "resist" or re-read the written text, but also needed to find ways of "reading" the performance context. theatre studies looked to film and media studies where feminist scholarship focused on the construction of "woman" as a sign: an approach in which feminism, psychoanalysis, and semiotics was and is being used to understand how women are represented in cinematic texts and other cultural contexts.
} 
Depois de algum tempo de diálogo percebemos que, por mais voltas que tentássemos dar, a história terminava com Joana sendo levada para fogueira. Com esse desfecho cruel, vinham questionamentos do tipo: como retratar essa morte para crianças? Como resolver essa morte em cena? Vamos desaparecer com ela? E a Mulan, vai ficar sozinha?

Nosso desejo era oferecer à figura de Mulan um destino diferente do relatado no filme de animação da Walt Disney Animation Studios. Nos baseamos principalmente em um poema traduzido por Cecília Meireles (apud Galvão, 1998) sobre a Balada de Mu-lan em que a figura do capitão - homem/príncipe - não é o centro e nem o que justifica as ações da guerreira mulher, que consegue total êxito em seu disfarce e volta para casa vitoriosa após a guerra. Porém, a solução que apontava para a morte de Joana e a vitória de Mulan não entrava em consonância com a crítica que queríamos fazer aos papéis de gênero exigidos para as mulheres na sociedade patriarcal. Refletimos sobre quais modificações ou licenças poéticas poderíamos utilizar na construção do final da dramaturgia.

Walnice Galvão (1998) enumera a quantidade de transformações pelas quais a donzela necessita passar: cortar os cabelos, vestir-se de homem - transformações visuais; esconder os seios e as ancas - suprimindo qualquer traço visível do feminino em seu corpo; e também a rejeição às "fraquezas femininas", que aparecem como possíveis dados comportamentais do ser mulher - modos, trejeitos, características, aspectos de uma possivel personalidade que tiveram que ser enfrentados e também suprimidos. Também são escondidos os cuidados com os próprios ferimentos de guerra, que necessitavam ser realizados somente por ela, sob o risco de ser descoberta. É uma trajetória solitária.

Como única mulher sob disfarce em meio a centenas de homens, qualquer mínimo deslize não seria perdoado. Poderia ser punido com a violência sexual, como temia Joana d'Arc, e com a morte. Ao se lançar nesse limiar entre poder de vida e risco de morte, a figura arquetípica da Donzela Guerreira parece assumir para si qualquer resultado, o que nos levou, como dramaturgas, a optar pela morte de Mulan em paralelo a execução de Joana d'Arc, embora as versões dessa lenda tragam a sua figura como vitoriosa. Decidimos então assumir as duas mortes: Joana na fogueira e Mulan capturada pelos soldados. Para nós, a sobrevivência da donzela devido à eficiência do disfarce poderia reforçar a necessidade constante de continuar a disfarçar-se e esconder-se nas batalhas seguintes.

Partimos de relatos e de nossa percepção sobre as dificuldades que uma mulher possa vir a enfrentar se decide adentrar em territórios majoritariamente masculinos: o risco de ser ridicularizada, inferiorizada, silenciada, assediada (moral ou sexualmente) é bastante amplo. A morte seria a negação da sua existência naquele determinado espaço. Como afirma Walnice Galvão,

[...] a imolação da personagem está associada à sua atuação na vida pública. Destina-se à morte, real ou simbólica; mas, ao irromper da esfera privada de atuação, ganha outras dimensões, crescendo cada vez mais até atingir a grandeza e provocar um terremoto em nossa estreita conformidade. (Galvão, 1998, p. 12) 
Assim, os mitos que embarcaram em suas jornadas solitárias morrem e outras mulheres/guerreiras assumem esse espaço deixado. Mulheres que lutam, cotidianamente, para não serem subjugadas, para ocuparem seus lugares enquanto seres sociais.

O poder de provocar terremotos e desestabilizar paradigmas de gênero irrompe na figura arquetípica da Donzela Guerreira que, em nossa dramaturgia, é Guerreira antes de Donzela, razão pela qual, no título, as palavras foram propositalmente invertidas. Além disso, escolhemos ser em plural ao invés de singular, pois, como diz um lema feminista bastante difundido, principalmente nas redes sociais, "juntas somos mais fortes". O lema diz respeito à ideia de sororidade, que visa quebrar o ciclo de rivalidade feminina e estabelecer relações de cooperação entre mulheres. Com a sororidade, a trajetória sai do ciclo da morte e adentra ao ciclo da resistência. Ao final da peça, quando as duas mulheres guerreiras, já contemporâneas uma à outra, se encontram no mesmo espaço, elas escolhem não serem rivais, e sim, aliadas.

Ao longo do segundo semestre de 2017, no decorrer de algumas apresentações, sugestões de alteração da dramaturgia, feitas por pessoas que acompanhavam as apresentações, foram sendo incorporadas ao texto. Como exemplo citado anteriormente, a professora do Departamento de Artes Cênicas da UDESC, Doutora Barbara Biscaro, fez algumas observações que contribuíram com a ideia de colocarmos Joana e Mulan em questionamento antes de partirem para a guerra, sobre os reais motivos que as impeliram e que escapassem à lógica patriarcal. A partir disso, incorporamos duas pequenas cenas. Joana, a primeira a partir, é questionada pela Narradora:

JOANA - Um dia, essas vozes me disseram que eu deveria montar num cavalo, empunhar uma espada e defender a França da invasão dos ingleses!

NARRADORA - Espera aí... você tá indo pra uma guerra?

JOANA - Oui!

NARRADORA - Mas por quê?

JOANA - Porque as vozes me disseram!

NARRADORA - Mas só porque umas vozes te mandaram fazer alguma coisa, você vai obedecer?!

JOANA - Oui!!

NARRADORA - Mas é uma guerra!! Não é uma lutinha de espadas!! Por que você quer ir pra essa guerra?!

JOANA - (impaciente) Porque eu quero montar num cavalo, pegar uma espada, liderar um exército e defender a França da invasão dos ingleses!!!

Mais adiante, é a vez de Mulan ser questionada por outra narradora:

MULAN - (surpresa) Eu?! Ora, o que é que eu vou fazer... Eu tou indo pra guerra!! (corre).

NARRADORA - Não, não, não!! (Usa um apito para parar) Por que você quer ir pra guerra? 
MULAN - Porque meu pai está velho e doente, e eu vou no lugar dele. (corre)

NARRADORA - (Apita e para Mulan) Então se seu pai não estivesse doente, você não ia querer ir pra guerra? Por que você quer ir pra essa guerra?

MULAN - Porque eu não tenho irmão homem que vá no meu lugar. (corre)

NARRADORA - Então se tivesse um irmão grande e forte você não iria querer?! Por que você quer ir pra essa guerra?!

MULAN - Ora! Eu quero ir pra guerra porque eu quero ir pra guerra! Porque dizem que é na guerra onde as coisas acontecem, dizem que é da guerra onde chegam todas as notícias, é na guerra onde o mundo está se transformando hoje, e eu quero fazer parte disso!

São duas cenas que carregam a potência de fazer com que as próprias personagens se investiguem e descubram a si mesmas, antes de tomarem as decisões por qualquer condicionamento social sobre seus corpos, mesmo aqueles mais sutis. $\mathrm{Na}$ narrativa que construímos, quando uma questiona a outra, também auxilia na decisão convicta de que, antes de ser pelos desejos ou necessidades de outros, é por elas mesmas e seus desejos pessoais que as guerreiras partem para a guerra.

\section{Primeiras apresentações e seus desdobramentos}

No dia 25 de agosto de 2017, estreamos com a primeira versão em formato de contação de estórias, no I Ciclo de Teatros Feministas em Cena, a mostra onde foram apresentados os resultados das avaliações práticas da disciplina Introdução ao Teatro Feminista. O evento contou também com mostras fotográficas e audiovisuais, oriundas dos diálogos entre os conteúdos estudados durante a disciplina e as práticas artísticas de discentes.

Utilizamos o Laboratório 1 do Departamento de Artes Cênicas da UDESC e apresentamos a composição da dramaturgia para um público de aproximadamente 30 pessoas. O figurino foi inicialmente composto de forma improvisada, com peças de roupa pessoais ou emprestadas. Os principais elementos de cena que ainda não existiam foram construídos por nós: as máscaras sem expressão dos soldados e do Pai de Mulan, que eram máscaras de carnaval (adquiridas em lojas de produtos para festas) cobertas com recortes de papel kraft e a armadura de Joana, que foi confeccionada em borracha E.V.A.. Também compramos uma espada de plástico que seria a arma de Joana, enquanto um leque seria a arma de Mulan.

Após a apresentação houve uma roda de conversa onde as pessoas puderam contribuir relatando suas impressões, o que funcionou, o que poderia melhorar. Com o incentivo de Brígida Miranda demos seguimento aos ensaios. Entre os dias 2 a 11 de outubro de 2017, organizamos a I Mostra Rosa Teatral, evento realizado pela A Lontra Faz Teatro, Grupo de Estudos Egrégora Feminista e Bapho Produções, com apoio da UDESC/CEART/PPGT. Tal mostra direcionou a discussão de gênero e saúde no contexto do "Outubro Rosa", campanha nacional em prol do diagnóstico e combate ao câncer de mama. Guerreiras Donzelas (2017) fez parte da programação do evento tendo sua apresentação na Casa de Teatro Armação na cidade de Florianópolis (SC). 
Ambas apresentações, no I Ciclo de Teatros Feministas em Cena e na I Mostra Rosa Teatral, ocorreram sob um olhar diretivo de Jussyanne Emidio. Objetos cênicos, figurinos, sonoplastia, ainda estavam em fase de acabamento e adaptação.

Após essas apresentações primeiras, Brígida Miranda se propôs a dirigir Guerreiras Donzelas (2017). Seu trabalho como diretora feminista encaixou-se muito bem com o que tínhamos proposto. A direção de Miranda foi muito generosa e importante para acertarmos detalhes que trouxeram maior amplitude para cena e foi, aos poucos, desenhando detalhes que enriqueceram a peça como um todo. Primeiro veio a ideia de termos sonoplastia ao vivo. Anteriormente, havíamos utilizado um tambor no momento em que as donzelas estavam se transformando em guerreiras. Miranda sugeriu que houvesse mais músicas sendo tocadas ao vivo no espetáculo e que as mesmas também compusessem a dramaturgia. As falas e as ações já desenvolvidas por nós não abriam muito espaço para que colocássemos mais um elemento sem perdermos o ritmo da peça. Precisaríamos de uma terceira pessoa conosco realizando a sonoplastia.

Após um ensaio, durante a pausa para o café, Renato Massashi Murahara, músico e companheiro de Brígida Miranda, estava nos mostrando um instrumento de cordas de origem japonesa chamado shamisen. Tal instrumento é muito utilizado como acompanhamento do teatro kabuki no Japão. A sonoridade proporcionada pelo shamisen trouxe uma ambientação oriental que estávamos buscando, principalmente nas cenas onde a chinesa Mulan era protagonista. Começamos a improvisar e cantarolar algumas canções da peça. Nos interessamos pelos sons que surgiram naquele momento e convidamos Massashi para fazer parte do elenco. O músico passou a ensaiar conosco e foi transformando a sonoplastia. Além do shamisen, Massashi trouxe para a peça violino, shakuhachi (instrumento de sopro oriental), nohkan (uma flauta transversal) e espátulas de metal que produzem o som de espadas batendo-se uma contra outra.

Foi o início de muitas outras parcerias que se somaram na composição do espetáculo. Além do Renato Massashi, a professora Dra. Débora Zamarioli, atriz e artista marcial, nos auxiliou na peça coreografando as cenas de combate, com algumas técnicas de leque para Jussyanne Emidio e movimentos de espada para Luane Pedroso. Essa marcação coreográfica, a nosso ver, intensificou a cena de guerra, delimitou aquele espaço e diferenciou as lutas da chinesa Mulan e da francesa Joana D'Arc. Também convidamos a artista e cosplayer Joana Kretzer Brandenburg para a criação dos figurinos. Brandendurg desenhou e confeccionou figurinos e armaduras mais sofisticadas para Joana e Mulan, também em borracha E.V.A., o que deu maior força para as cenas de transformação das donzelas em guerreiras. A colaboração recente do professor Doutor Valmor Nini Beltrame, com propostas para a animação do boneco que representa o Pai de Mulan e para o uso das máscaras, tem se somado para a completude do trabalho. 


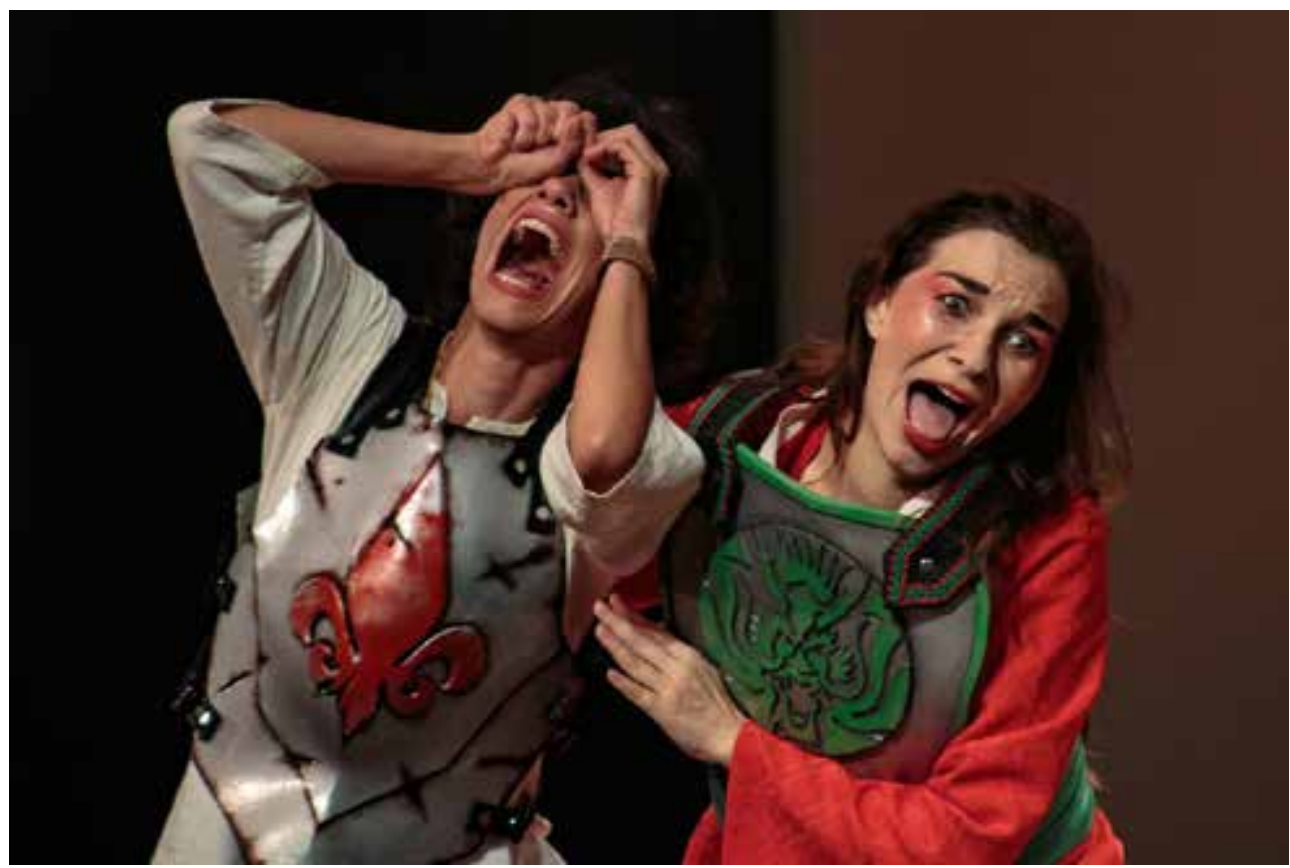

Luane Pedroso e Jussyanne Emidio. Teatro da UFSC. Florianópolis. 20 maio 2018. Foto: Mhirley Lopes. Acervo pessoal das autoras.

Desde fevereiro de 2018, sob a direção de Miranda, a peça reestreou em novo formato no dia 06 de fevereiro de 2018 dentro da programação do FIK - Festival Internacional de Arte e Cultura José Luiz Kinceler ${ }^{9}$, mantendo o mesmo núcleo dramatúrgico que havíamos elaborado. A apresentação aconteceu no Espaço 1 do Departamento de Artes Cênicas da UDESC e atingiu um público de aproximadamente 80 pessoas. O Festival abarcou grande número de produções, sendo um sucesso de público. A recepção foi bastante positiva, na plateia haviam muitas crianças, o que para nós foi muito importante, já que a construção da peça é direcionada a esse público. Pensamos em reelaborar os tempos de algumas cenas, pois percebemos que alguns deles não funcionaram tão bem. Cenas mais longas e as cenas em que utilizamos máscara neutra por exemplo, são pontos que ainda precisamos ajustar se quisermos continuar direcionando a crianças mais novas.

A peça fomentou a criação do grupo teatral Mulheres em Cena (homônimo ao projeto de extensão universitária coordenado por Miranda), ganhando força com a direção de Miranda, a direção musical de Renato Massashi Murahara e a direção coreográfica de Débora Zamarioli. O espetáculo tem ganhado cada vez mais estrutura e circulado em espaços da cidade de Florianópolis, como o projeto A Barca dos Livros, o Teatro da UFSC, apresentações na UDESC e recentemente selecionado para o 23을 Festival Isnard Azevedo - realizado pela Prefeitura de Florianópolis, por meio da Secretaria Municipal de Cultura, Esporte e Juventude e Fundação Cultural de Florianópolis Franklin Cascaes.

Contando mais de um ano de trajetória desde a sua primeira concepção, as respostas ao espetáculo têm sido animadoras. A pesquisadora em teatro infantil e mestranda do PPGT/UDESC, Paula Gotelip, recentemente publicou uma crítica sobre

${ }^{9}$ O Festival Internacional de Arte e Cultura José Luiz Kinceler ocorreu entre os dias 4 e 7 de fevereiro de 2018 na Universidade do Estado de Santa Catarina-UDESC. Site do evento disponivel em: <http://www.udesc.br/ceart/fik> 
a peça na coluna Mulheres em Cena que, desde junho de 2018, é espaço de crítica de arte feminista do Portal Catarinas, um relevante portal de jornalismo com perspectiva de gênero do estado de Santa Catarina. Desde que assistiu uma apresentação com a sua filha Julia de 6 anos, em fevereiro de 2018, Gotelip havia comentado sobre a reação de sua filha à peça. Gotelip $(2018$, p. 1) descreve:

\footnotetext{
Mulan e Joana d'Arc reverberaram por duas semanas nos pensamentos e nos diálogos da minha filha. Neste período, sem que eu tocasse no assunto, a pequena indagou questões sociais dela e familiares a partir da construção do espetáculo ("Por que os homens ficam sem camisa e mulheres não neste calor"? "Por que meu avô não lava a louça"? "Porque minha tia precisar ir rápido para casa para fazer almoço se o marido dela está em casa”?). O espetáculo é pensado para crianças, mas cabe como uma luva para adultos: abre espaço para construção crítica e reflexiva sobre os feminismos ampliando espaços de fala e escuta sobre nossos papéis sociais. Mas, além disso, nos convida a não esperar mais tempo, a começar agora a refletir e debater sobre a libertação feminina e nossos espaços ao longo da história.
}

Com a resposta positiva do público infantil, observada nas apresentações já ocorridas até o momento, o próximo passo é a ampliação do texto: trazer no início da peça uma espécie de reverência às mulheres que lutaram antes de nós, e, ao final, a inclusão da história de mulheres brasileiras que também tiveram participações ativas em guerras reais ou em outros espaços predominantemente masculinos. Histórias de heroínas brasileiras como Maria Quitéria, Jovita Feitosa, Maria Bonita, Anita Garibaldi, Clara Camarão e outras, que ainda estamos descobrindo em pesquisa.

O espetáculo Guerreiras Donzelas, concebido em meio à pesquisa acadêmica e que segue em circulação em diversos espaços fora da universidade, nos mostra que a pesquisa acadêmica em artes se desenvolve em conexão com a atualidade do tempo em que vivemos. Sejam os seus conflitos, sejam as suas benesses, a profusão e a emergência dos debates em movimentos sociais e nas redes, em contato coadunam com o desejo de desenvolver práticas teatrais feministas.

\section{Referências}

AMARAL, Flávia Aparecida. História e ressignificação: Joana d'Arc e a historiografia francesa da primeira metade do século XIX. 2012. 221 f. Tese (Doutorado) - Curso de História Social, Departamento de História, Universidade de São Paulo, São Paulo, 2012. Disponível em: <http://www.teses.usp.br/teses/disponiveis/8/8138/tde-14012013105821/pt-br.php>. Acesso em: 25 nov. 2017.

ANIMA. Making of CD Donzela Guerreira. Youtube. Disponível em: <http://www. animamusica.art.br/site/lang_pt/pages/clips/making_donzela.html> Acesso em: 22 jan.2018.

ASTON, Elaine. An introduction to feminism and theatre. London: Routledge, 1995. 
CONTRERA ÁVILA, Rebeca. Minha história das mulheres: Michelle Perrot. História Social, Campinas, n. 16, p. 249-253. jun. 2009. Disponível em: <https://www.ifch. unicamp.br/ojs/index.php/rhs/issue/view/19>. Acesso em: 13 fev. 2018.

FERREIRA ELEUTHÉRIO, Mayquel. O Filósofo e a Donzela: a corrosão do mito de Joana d'Arc por Voltaire em La Pucelle d'Orléans. Aedos, Rio Grande do Sul, v. 4, n. 10, p. 131-152, jan. 2012. Disponível em: <http://seer.ufrgs.br/index.php/aedos/article/ view/24603/18995>. Acesso em: 09 out. 2017.

GALVÃO, Walnice Nogueira. A donzela-guerreira: um estudo de gênero. São Paulo: Editora SENAC, 1998.

GOTELIP, Paula. Esperar, um verbo feminino? Coluna Mulheres em Cena - Portal Catarinas. Disponível em: <http://catarinas.info/colunas/esperar-um-verbo-feminino/>. Acesso em: 27 jul.18.

JUNG, Carl Gustav. Arquétipos e o inconsciente coletivo 9/1. In: Obras completas de Carl Gustav Jung. Petrópolis, RJ: Vozes, 2011.

MIRANDA, Maria Brígida de. Seminário Temático 01: Introdução ao Teatro Feminista (Ementa da disciplina. Não publicada). Programa de Pós-graduação em Teatro (PPGT/ UDESC), 2017.

MULAN. Direção: Tony Bancroft, Barry Cook. Produção: Pam Coats. Burbank, California (EUA): Walt Disney Animation Studios, 1998, 1 DVD.

VOLTAIRE. La Pucelle D'Orléans. Disponível em <http://www.dominiopublico.gov.br/ download/texto/lv000037.pdf> Acesso em 2 out. 2018.

EMIDIO, Jussyanne; PEDROSO, Luane. Guerreiras Donzelas. Dramaturgia (texto não publicado).

Recebido em: 30/09/2018

Aprovado em: $27 / 10 / 2018$ 